\title{
Methamphetamine Use and Sexual Activity Among HIV-Infected Patients in Care-San Francisco, 2004
}

\author{
SAMUEL J. MITCHELL, M.D., Ph.D., ${ }^{1,2}$ SHELDON R. MORRIS, M.D., M.P.H., ${ }^{3}$ \\ CHARLOTTE K. KENT, M.P.H., ${ }^{1}$ JOHN STANSELL, M.D., ${ }^{4}$ \\ and JEFFREY D. KLAUSNER, M.D., M.P.H. ${ }^{1}$
}

\section{INTRODUCTION}

M ETHAMPHETAMINE is a central nervous stimulant that has become the secondmost common drug of abuse world-wide (after cannabis), ${ }^{1}$ and in 2002 become the leading cause of inpatient drug-treatment admissions in California. ${ }^{2}$ Methamphetamine is an easily obtained illicit substance that is smoked, snorted, ingested orally, inserted rectally, inserted vaginally, and injected intravenously. A growing body of literature has linked methamphetamine use with risky sexual behaviors that increase the likelihood of transmitting HIV and other sexually transmitted diseases (STDs). However, less is known about the extent of methamphetamine use among HIV-infected persons who might be at risk of harming themselves from methamphetamine's effects or infecting others with HIV while under the influence of methamphetamine.

Methamphetamine use among men who have sex with men (MSM) is relatively common and is associated with risky sexual behavior. The Urban Men's Health Study ${ }^{3}$ reported that 9.5\% of MSM in four large U.S. cities reported methamphetamine use in the prior 6 months during 1996-1998 (13.3\% in San Francisco MSM), and the EXPLORE study reported that $13 \%$ of MSM in six large US cities reported methamphetamine use in the prior 6 months during 1999-2001 (23\% of MSM in San Fran- cisco). ${ }^{4,5}$ Multiple studies have demonstrated that methamphetamine use among MSM is associated with unprotected anal intercourse (both insertive and receptive) and with intercourse with HIV-serodiscordant partners. ${ }^{4-10}$ Prevalence estimates of methamphetamine use by HIV-positive MSM are variable. In 1998, the Supplement to HIV / AIDS Surveillance (SHAS) project reported that $15 \%$ of 9735 HIV-positive MSM from 12 U.S. states had used amphetamines (including methamphetamine) at some time in their lives. ${ }^{11}$ In 2004, the Seropositive Urban Men's Intervention Trial (SUMIT) reported that $10.1 \%$ of $1168 \mathrm{HIV}$-positive MSM from New York City and San Francisco reported methamphetamine use in the past 3 months. ${ }^{10}$ Semple et al. ${ }^{12}$ reported in 2003 that binge use of methamphetamine was common (45.5\%) among 90 HIV-positive MSM in Los Angeles, as was unprotected sex with serodiscordant partners and follow-up surveillance in 2004 also demonstrated increased multipartnerism associated with methamphetamine use by this cohort. ${ }^{13}$ In a Denver public health survey methamphetamine use by MSM in the prior year was reported as $11 \%$ and in MSM living with HIV it was $21 \%{ }^{14}$ The Denver survey also suggested that methamphetamine using MSM were three times more likely to have unprotected sex compared to nonmethamphetamine using MSM.

\footnotetext{
${ }^{1}$ STD Prevention and Control Services, San Francisco Department of Public Health, San Francisco, California.

${ }^{2}$ Epidemic Intelligence Service, Centers for Disease Control and Prevention, Atlanta, Georgia.

${ }^{3}$ Department of Family and Community Medicine, University of California, San Francisco, California.

${ }^{4}$ Department of Medicine, University of California, San Francisco, California.
} 
The use of methamphetamine has been documented in many demographic groups with links between methamphetamine use and riskier sex demonstrated among African American, Filipino, and Latino MSM. ${ }^{15-17}$ Methamphetamine use has been associated with increased sexual multipartnerism among MSM, heterosexual men, and heterosexual women. ${ }^{1}$ Methamphetamine is associated with intravenous injection ${ }^{18,19}$ and up to $40 \%$ of injecting methamphetamine users have been shown to transition directly to injection from other routes of methamphetamine use. ${ }^{20}$ Women who have sex with women (WSW) in northern California were significantly more likely to report having injected methamphetamine during the prior 6 months compared to heterosexual women. ${ }^{21}$ In a sample of heterosexual men from low income neighborhoods of northern California with a high representation of Hispanic and black, nonHispanic race/ethnicity, recent methamphetamine users were more likely than nonmethamphetamine users to have anonymous female partners and have two or more female partners in the past 6 months. ${ }^{22}$ In this study an attempt was made to assess condom use but because of overall low use of condoms by all participants no clear association between recent methamphetamine use and unprotected sex was found.

Methamphetamine use has also been associated with incident HIV and sexually transmitted disease (STD) infection. A large international study of MSM in Europe, the United States, Canada, and Australia demonstrated an association between methamphetamine use and HIV infection. ${ }^{23}$ In San Francisco, two separate studies demonstrated increased HIV incidence associated with methamphetamine. ${ }^{24,25}$ Similarly, methamphetamine use has been associated with early syphilis infection in New York City and San Francisco. ${ }^{26,27}$

HIV-positive individuals incur direct harm from methamphetamine that has been shown to hasten HIV dementia ${ }^{28}$ and selectively damage dopaminergic central-nervous system neurons in HIV-infected individuals. ${ }^{29}$ Methamphetamine also interferes with adherence to highly active antiretroviral therapy (HAART) as a result of patient concerns about methamphetamine-HAART interactions (planned nonadherence) and forgetting to take HAART while under the influence of methamphetamine (unplanned nonadherence). ${ }^{30}$ Increased HIV viral loads because of HAART nonadherence has been described among persons using methamphetamine. ${ }^{31}$ Methamphetamine use is also associated with physical changes such as dental caries. ${ }^{32,33}$

Prior studies on methamphetamine use and HIV/STDs have primarily focused on the risk of HIV-uninfected persons becoming infected as a result of riskier sexual behavior while using methamphetamine. This cross-sectional survey was performed to rapidly assess the prevalence of methamphetamine use and the sexual activity among persons who are already HIV-positive and therefore at risk of transmitting HIV to uninfected partners or acquiring other STDs themselves. In addition, because provider knowledge of patients' sexual practices and substance use provides an opportunity for counseling on risk reduction, patient-provider communication was assessed.

\section{METHODS}

\section{Survey distribution}

We systematically distributed English and Spanish versions of a 1-page, anonymous survey to HIV-positive patients seeking care at two San Francisco clinics. These two clinics operate the University of California at San Francisco's (UCSF) Positive Health Program (PHP) at San Francisco General Hospital Medical Center (SFGH), which serves uninsured and public-insured individuals; and PHP Moffit (Moffit), which primarily serves those with private or public insurance. Together, these two sites provide clinical service to the largest number of HIV-positive persons in San Francisco. The survey was distributed at SFGH from February 16 to March 16, 2004, and at Moffit from August 13 to October 24, 2004. A survey was given to each patient at registration and completed on a voluntary basis prior to the clinical visit. A snack bar was used as an incentive for each returned survey. Survey respondents were asked to indicate if they had previously completed a survey, but were given an incentive even if they were a repeat respondent. There- 
fore, no incentive existed for a person to misrepresent a survey as unique in order to garner more snack bars. The surveys were returned at the end of the visit and collected every 1-4 days. Because some patients might have completed the survey under the influence of psychoactive substances, most (20 of 23) questions were designed with single check-box answers to maximize the response rate.

In addition to basic demographic data (English- or Spanish-speaker, age, gender, gender of sex partners), the 23-question survey collected information on sexual activity (number of partners in past 4 weeks and past 12 months); methamphetamine use (past 4 weeks and past 12 months, frequency of use during past 4 weeks, and routes of use); and patient-provider communication on sexual activity and methamphetamine use. Respondents who had used methamphetamine at any time within the preceding 12 months were asked about frequency of use in the past 4 weeks; method of use (oral ingestion, inhalation of smoke, intranasal snorting, intravenous injection, or rectal insertion of dissolved methamphetamine); and to answer a structured fivequestion screening tool for methamphetamine dependence (the Substance Dependence Scale or SDS). The SDS was developed for assessing opiate dependence ${ }^{34}$ and was subsequently validated against a standard psychiatric handbook (the Diagnostic and Statistical Manual of Mental Disorders [DSM-III]) for assessing amphetamine dependence. ${ }^{35}$ Respondents were also asked to provide written comments on those methamphetamine reduction/cessation programs they had found helpful. A subset of patients at the Moffit site were asked an additional question about their use of methamphetamine during sex.

\section{Statistical analyses}

Using EpiInfo 6, ${ }^{36}$ we compared two or more categorical variables using prevalence risk ratios (RR) with 95\% confidence intervals (CI), or as percent prevalence and $p$ value using the two-tailed Fisher's exact test for univariate data or Chi-square test for trend. The Student's $t$ test was used to compare means and the Wilcoxon
Rank Sum Test (WRST) was used to compare medians.

For the analyses, three gender/orientation groups were constructed based upon each respondent's gender and the gender of their sex partners: MSM (including bisexual men), heterosexual men, and women (heterosexual and WSW). A subanalysis comparing the 22 WSW respondents with the 54 heterosexual women respondents revealed no significant differences between these subgroups (data not shown), and they were combined into the single category of women. A subanalysis performed on each group to compare responses at the two survey sites (SFGH and Moffit) revealed that only one question had significantly different responses by site (patient comfort discussing methamphetamine use with their provider); therefore, the responses from the two sites were combined for all analyses. We also performed each analysis stratified by groups to control for confounding and examine effect modification.

\section{Human subjects review}

The investigation was reviewed by the CDC (Human Subjects Review numbers 2004-00133 [SFGH] and 2004-00195 [Moffit]) and designated as nonresearch public health surveillance in accordance with the Code of Federal Regulations, Title 45, Part 46: The Public Service Act.

\section{RESULTS}

\section{Participation}

Of 731 distributed surveys, 642 (87.8\%) were returned to the collection boxes. Of 642 respondents, $58(9.1 \%)$ indicated that they had filled out the survey before, and these duplicate surveys were excluded from further analysis. Thirteen respondents were transgender and excluded from the analysis because of small sample size and inability to distinguish female-to-male from male-to-female transgender. Review of the unique surveys to remove partial reporting (e.g., $<50 \%$ of questions answered) further reduced the sample to the final analysis set of 537 respondents $(73.5 \%$ of distributed surveys). 


\section{Demographics}

Of the 537 respondents, 368 (68.5\%) were MSM, 88 (16.4\%) heterosexual men, and 81 $(15.1 \%)$ women (Table 1$)$. The median age of the three groups was similar $(43,45.5$, and 44 years, respectively), and $98.7 \%$ were Englishspeaking.

\section{Sexual practices}

Most $(92.5 \%)$ patients stated they would be comfortable discussing sexual practices with their provider, yet less than half $(47.2 \%)$ were asked. Significantly more sex partners were reported by MSM in the preceding 4 weeks $(1.8 \pm$ 3.5 [mean \pm standard deviation] for MSM, $0.7 \pm 1.2$ for heterosexual men, and $0.7 \pm 0.9$ for women; $p<0.01$ ) and in the preceding 12 months $(9.8 \pm 23.4$ for MSM, $1.6 \pm 3.0$ for het- erosexual men, and $1.2 \pm 2.3$ for women; $p<$ $0.01)$. A subanalysis on provider communication with patients who reported 2 or more partners revealed that providers were more likely to ask patients with 2 or more partners in the past 4 weeks about their sexual practices $(61.4 \%$ of those with $\geq 2$ partners versus $42.7 \%$ of those with $\leq 1$ partner, $p=0.03$ ), with a nonsignificant trend toward asking patients with 2 or more partners in the past 12 months about their sexual practices $(55.7 \%$ versus $42.3 \%, p=$ 0.13). There was no evidence of confounding when stratified by group.

\section{Methamphetamine use}

Overall, $18.3 \%$ of patients reported that they had used methamphetamine in the preceding 4 weeks and $35.1 \%$ that they had used metham-

Table 1. Characteristics of HiV-Positive Patients in Care in San Francisco-2004

\begin{tabular}{|c|c|c|c|c|c|c|c|}
\hline \multirow[b]{2}{*}{ Respondents, $\mathrm{n}=537$} & \multirow[b]{2}{*}{$\begin{array}{c}M S M \\
\mathrm{n}=368\end{array}$} & \multirow[b]{2}{*}{$\begin{array}{c}\% \\
68.5\end{array}$} & \multicolumn{4}{|c|}{ Heterosexual } & \multirow[b]{2}{*}{$P$} \\
\hline & & & $\begin{array}{c}\text { Men } \\
\mathrm{n}=88\end{array}$ & $\begin{array}{c}\% \\
16.4\end{array}$ & $\begin{array}{l}\text { Women } \\
\mathrm{n}=81\end{array}$ & $\begin{array}{c}\% \\
15.1\end{array}$ & \\
\hline Age in years; median (IQR) & \multicolumn{2}{|c|}{$43(38.5-48.5)$} & \multicolumn{2}{|c|}{$45.5(40.5-51.0)$} & \multicolumn{2}{|c|}{$44(40.0-50.0)$} & \\
\hline English-speaking & 385 & 99.2 & 85 & 96.9 & 80 & 98.8 & \\
\hline Spanish-speaking & 3 & 0.8 & 3 & 3.4 & 1 & 1.2 & \\
\hline $\begin{array}{l}\text { Comfortable talking to provider } \\
\text { about sex }\end{array}$ & $334 / 361$ & 82.5 & $80 / 85$ & 94.1 & $70 / 77$ & 90.9 & 0.74 \\
\hline Provider asks about sex & $183 / 358$ & 51.1 & $29 / 83$ & 34.9 & $32 / 78$ & 42.1 & 0.02 \\
\hline $\begin{array}{l}\text { Comfortable talking to provider } \\
\text { about methamphetamine use }\end{array}$ & $299 / 339$ & 88.2 & $68 / 78$ & 87.2 & $56 / 70$ & 80.0 & 0.18 \\
\hline $\begin{array}{l}\text { Provider asks about } \\
\text { methamphetamine use }\end{array}$ & $145 / 359$ & 40.4 & $27 / 83$ & 32.5 & $28 / 76$ & 34.2 & 0.31 \\
\hline $\begin{array}{l}\text { No. partners past } 4 \text { weeks: } \\
\text { mean (SD) }\end{array}$ & 1.8 & $(3.5)$ & 0.7 & $(1.2)$ & 0.7 & $(0.9)$ & $<0.01$ \\
\hline $\begin{array}{l}\text { No. partners past } 12 \text { months: } \\
\text { mean (SD) }\end{array}$ & 9.9 & $(23.4)$ & 1.6 & $(3.0)$ & 1.1 & $(5.2)$ & $<0.01$ \\
\hline $\begin{array}{l}\text { Used methamphetamines in } \\
\text { past } 4 \text { weeks }\end{array}$ & $68 / 347$ & 19.6 & $13 / 81$ & 16.0 & $11 / 73$ & 15.1 & 0.56 \\
\hline $\begin{array}{l}\text { Used methamphetamines in } \\
\text { past } 4 \text { weeks and dependent }\end{array}$ & $41 / 65$ & 63.1 & $5 / 11$ & 45.5 & $7 / 10$ & 70.0 & 0.46 \\
\hline $\begin{array}{l}\text { Used methamphetamines in } \\
\text { past } 12 \text { months }\end{array}$ & $137 / 347$ & 38.5 & $23 / 76$ & 30.3 & $14 / 73$ & 19.2 & $<0.01$ \\
\hline $\begin{array}{l}\text { Used methamphetamines in } \\
\text { past } 12 \text { months and dependent }\end{array}$ & $79 / 133$ & 59.4 & $13 / 21$ & 61.9 & $10 / 13$ & 78.9 & 0.47 \\
\hline \multicolumn{8}{|l|}{$\begin{array}{l}\text { Route of methamphetamine use } \\
\text { in past } 12 \text { months }\end{array}$} \\
\hline Oral ingestion & $15 / 132$ & 11.4 & $2 / 22$ & 8.1 & $1 / 13$ & 7.7 & 0.85 \\
\hline Smoked & $88 / 132$ & 51.5 & $7 / 22$ & 31.8 & $5 / 13$ & 38.5 & 0.18 \\
\hline Snorted & $62 / 132$ & 47.0 & $1 / 22$ & 4.5 & $3 / 13$ & 23.1 & $<0.01$ \\
\hline Intravenous injections & $46 / 132$ & 34.8 & $14 / 22$ & 63.6 & $7 / 13$ & 53.8 & 0.02 \\
\hline Rectal insertion & $28 / 132$ & 21.2 & $0 / 22$ & 0.0 & $1 / 13$ & 7.7 & 0.03 \\
\hline
\end{tabular}

MSM, men who have sex with men; IQR, interquartile range; SD, standard deviation. 
phetamine in the preceding 12 months. Methamphetamine users were slightly younger (median age, 41 years, intraquartile range $[\mathrm{IQR}]=38-45$ ) than nonusers (45 years, IQR $=40-50.5$ ); $p<$ 0.01 . Most $(86.9 \%)$ patients responded that they would be comfortable discussing methamphetamine use with their provider, yet only $37.8 \%$ of patients reported being asked. More respondents from Moffit (92.3\%) reported being comfortable discussing methamphetamine use than those from SFGH $(73.6 \%), p=0.03$. A subanalysis on provider communication with those patients who reported methamphetamine use indicated that providers were asking methamphetamine users about methamphetamine more frequently than they asked nonusers (past 4 weeks: $69.0 \%$ versus $30.5 \%$ respectively, $p<0.01$; past 12 months: $62.4 \%$ versus $26.0 \%$ respectively, $p<$ 0.01). No evidence of confounding was found when stratified by group.

Significantly more MSM (39.5\%) reported methamphetamine use in the past 12 months than heterosexual men $(30.3 \%)$ or women $(19.2 \%) ; p<0.01$. Among methamphetamine users in the preceding 4 weeks, $61.6 \%$ met criteria for dependence by the SDS, as did $61.1 \%$ of methamphetamine users in the preceding 12 months. Dependence did not differ significantly by group.

The most common route for methamphetamine use in the preceding 4 weeks was smoking $(40.4 \%)$, followed by intravenous injection $(33.8 \%)$, snorting $(33.3 \%)$, rectal insertion $(14.8 \%)$, and oral ingestion (9.1\%). A significant association was found between dependence and intravenous injection of methamphetamine $(\mathrm{RR}=1.3,95 \% \mathrm{CI}=1.1-1.7)$ but not for oral, smoked, snorted, or rectally inserted methamphetamine. Women and heterosexual men more commonly reported injecting methamphetamine than MSM $(p=0.02)$ (Table 1$)$. By comparison, MSM more commonly reported snorting $(p<0.01)$ or rectal insertion $(p=0.03)$ than women or heterosexual men (Table 1).

Among those who met SDS criteria for methamphetamine dependence during the past 12 months, $26.9 \%$ reported frequent methamphetamine use (once per week or more in the preceding 4 weeks), $26.9 \%$ infrequent methamphetamine use (less than once per week), and $46.2 \%$ had not used in the past 4 weeks. Among the $46.2 \%$ of dependent persons who had not used methamphetamine in the past 4 weeks, 32 provided written comments, and $15(46.8 \%)$ of 32 were either recently or currently in substance-abuse treatment (e.g., inpatient treatment or Narcotics Anonymous). A subanalysis of dependent users revealed that providers were more likely to ask frequent users about methamphetamine than nonusers (78.6\% versus $58.2 \%, p<0.01$ ). No significant associations were found between frequency of use and route of use.

\section{Methamphetamine use and sexual practices}

Methamphetamine users were significantly more likely to have had multiple $(\geq 2)$ sex partners in both the past 4 weeks and past 12 months than nonusers. In the past 4 weeks, $48.9 \%$ of methamphetamine users versus $16.8 \%$ of nonusers reported multiple partners $(\mathrm{RR}=$ $2.9,95 \% \mathrm{CI}=2.1-3.9)$, with no evidence of confounding when stratified by group. In the past 12 months, $62.2 \%$ of methamphetamine users versus $32.0 \%$ of nonusers reported multiple partners $(\mathrm{RR}=2.0,95 \% \mathrm{CI}=1.6-2.4)$. However, this effect was significantly $(p=0.02)$ modified by sexual orientation and gender. The relative risk of multipartnerism associated with methamphetamine use during the past 12 months was $1.5(95 \% \mathrm{CI}=1.2-1.8)$ among MSM, 5.2 (1.9-14.5) among heterosexual men, and 4.9 (1.3-18.5) among women. A subset of 144 patients was asked whether they used methamphetamine during sex; $68.8 \%$ had used methamphetamine during sex in the past 4 weeks and $74.3 \%$ had used methamphetamine during sex in the past 12 months.

\section{DISCUSSION}

This investigation demonstrates that methamphetamine use was common among HIV-positive persons in medical care in San Francisco during 2004 and was associated with a greater number of recent sex partners. The high reported prevalence of methamphetamine use during sex $(>60 \%)$, and the strong association between methamphetamine use and risky sexual behavior, ${ }^{4-9,37,38}$ means that these HIV-pos- 
itive individuals might place serodiscordant partners at greater risk for becoming infected with HIV. The association of multipartnerism with methamphetamine use might also place these HIV-positive individuals at increased risk for becoming infected with or transmitting other STDs. ${ }^{23-27}$ In addition to confirming reports of frequent methamphetamine use among MSM, this study's finding of common use among women (19.2\%) and heterosexual men $(30.3 \%)$ is noteworthy because these are populations for which there is less known about sexual risk-taking related to methamphetamine use.

The finding that fewer than half of this sample is being asked about their sexual practices or methamphetamine use by their providers is also of concern. HIV-positive individuals might experience greater harm from methamphetamine use than HIV-uninfected individuals. ${ }^{28,29}$ Given the reports of HAART nonadherence related to methamphetamine use, ${ }^{30,31}$ they are also at increased risk for missing medication doses, which has been shown to increase HIV viral load. ${ }^{39,40}$ Because these persons are in medical care and report high comfort levels discussing their experiences with providers, they are excellent candidates for frank, open discussion of sexual risks and substance abuse as recommended by the Centers for Disease Control (CDC) and others. ${ }^{41}$ Several prior studies have documented the need for providers to discuss risk reduction with their HIV-positive patients. ${ }^{42,43}$ Although there was a trend for providers in this study to ask the most sexually active patients about sex and frequent methamphetamine users about methamphetamine, there remain many missed opportunities for discussion and intervention. Our findings should encourage providers to ask screening questions about sexual activity and methamphetamine use at every visit.

More than $60 \%$ of methamphetamine users in this study meet screening criteria for dependence. Effective interventions to reduce or halt methamphetamine use have been difficult to develop, although studies of cognitive-behavioral therapy and contingency-management programs have shown promise. ${ }^{38,44-46}$ Prolonged treatment success is possible, as demonstrated by the Matrix treatment program in which recent methamphetamine use among 114 HIV-positive individuals dropped from $86.8 \%$ at entry to $17.5 \% 2-5$ years after treatment. ${ }^{47}$ Unfortunately, in the absence of treatment, sexual risk-taking behavior by our sample group seems likely. Campsmith et al. ${ }^{48}$ reported that after HIV diagnosis, use of crack cocaine (a stimulant similar to methamphetamine) was a significant predictor of unprotected sex and multiple sex partners. Of concern, another study demonstrated that injection-drug use was a significant correlate of substance-abuse treatment drop-out among MSM in San Francisco. ${ }^{49}$ Our study found that methamphetamine injection was the only use route significantly associated with dependence; therefore, this group might present additional treatment challenges.

This study had several limitations: the crosssectional design cannot address causality; the self-completion format might reduce response rate; the use of the SDS for assessing dependence might be imprecise; the lack of information on high-risk sexual behaviors other than partner number; there is no information of HAART adherence; and the small sample size for women and heterosexual men limits statistical power. However, the cross-sectional design should limit recall bias by simultaneously obtaining information on sexual partners, methamphetamine use, and patient-provider communication. The anonymous self-completion format should have reduced the likelihood of respondents giving socially desirable answers to questions on methamphetamine use or multipartnerism. The five-question SDS has been shown to have a $71.3 \%$ sensitivity and $77.1 \%$ specificity when tested against the DSM-III, 35 and we encourage its use as a rapid screening tool for providers who seek to learn more about methamphetamine use by their patients. The association of methamphetamine use and higher risk sex and diminished HAART adherence has already been published by others. ${ }^{4-10,30,31}$ Our survey of MSM, heterosexual men, and women provides a better understanding of methamphetamine prevalence among HIV-positive patients in care and needed to be an instrument that is quickly and easily completed even by those that may be impaired by use of psychoactive substance. Making a longer survey by adding additional questions on HAART use, 
frequency of condom use and type of sexual activities may have limited the response rate and biased the estimate. Further surveillance is also needed to improve our knowledge of less-studied groups (e.g., women and heterosexual men).

In summary, we describe a high prevalence rate of methamphetamine use among HIV-positive persons in medical care in San Francisco regardless of sexual orientation and gender, and associations of this use with having sexual intercourse and multiple sex partners. Because these patients are in clinical care, knowledge that they use methamphetamine and engage in sexual risk behavior provides an opportune moment for clinical intervention. We believe that patients receiving HIV care should be routinely screened regarding their sexual practices and methamphetamine use, and counseling on risk-reduction or substance-abuse treatment should be provided when indicated.

\section{ACKNOWLEDGMENTS}

Supported by San Francisco Department of Public Health; and United States Public Health Service (salary support for S.J.M.).

S.J.M., S.R.M., C.K.K., J.S., and J.D.K. report no conflicts.

We thank the staff of the Positive Health Programs at SFGH Ward 86 (especially Richard Coddington and Rhonda Jones) and Moffit (especially Malcom John, Susan Shea, and David MacLeod) for their support of this investigation. We thank the patients of the PHP program for their assistance in improving the health care of many HIV-infected persons

\section{REFERENCES}

1. Molitor F, Truax SR, Ruiz JD, Sun RK. Association of methamphetamine use during sex with risky sexual behaviors and HIV infection among non-injection drug users. West J Med 1998;168:93-97.

2. Treatment Episodes Data Set. United States Department of Health and Human Services, Substance Abuse and Mental Health Services Administration., 2002. www.dasis.samhsa.gov/webt/quicklink/CA02. htm (Last accessed June 13, 2005).

3. Stall R, Paul JP, Greenwood G, et al. Alcohol use, drug use and alcohol-related problems among men who have sex with men: The Urban Men's Health Study. Addiction 2001;96:1589-1601.

4. Colfax G, Vittinghoff E, Husnik MJ, et al. Substance use and sexual risk: A participant- and episode-level analysis among a cohort of men who have sex with men. Am J Epidemiol 2004;159:1002-1012.

5. Colfax G, Coates TJ, Husnik MJ, et al. Longitudinal patterns of methamphetamine, popper (amyl nitrite), and cocaine use and high-risk sexual behavior among a cohort of san francisco men who have sex with men. J Urban Health 2005;82(1 Suppl 1):i62-70.

6. Rusch M, Lampinen TM, Schilder A, Hogg RS. Unprotected anal intercourse associated with recreational drug use among young men who have sex with men depends on partner type and intercourse role. Sex Transm Dis 2004;31:492-498.

7. Shoptaw S, Reback CJ, Freese TE. Patient characteristics, HIV serostatus, and risk behaviors among gay and bisexual males seeking treatment for methamphetamine abuse and dependence in Los Angeles. J Addict Dis 2002;21:91-105.

8. Paul JP, Stall R, Davis F. Sexual risk for HIV transmission among gay/bisexual men in substance-abuse treatment. AIDS Educ Prev 1993;5:11-24.

9. Frosch D, Shoptaw S, Huber A, Rawson RA, Ling W. Sexual HIV risk among gay and bisexual male methamphetamine abusers. J Subst Abuse Treat 1996; 13:483-486.

10. Purcell DW, Moss S, Remien RH, Woods WJ, Parsons JT. Illicit substance use, sexual risk, and HIV-positive gay and bisexual men: Differences by serostatus of casual partners. AIDS 2005;19(Suppl 1):S37-47.

11. Sullivan PS, Nakashima AK, Purcell DW, Ward JW. Geographic differences in noninjection and injection substance use among HIV-seropositive men who have sex with men: Western United States versus other regions. Supplement to HIV / AIDS Surveillance Study Group. J Acquir Immune Defic Syndr Hum Retrovirol 1998;19:266-273.

12. Semple SJ, Patterson TL, Grant I. Binge use of methamphetamine among HIV-positive men who have sex with men: Pilot data and HIV prevention implications. AIDS Educ Prev 2003;15:133-147.

13. Semple SJ, Patterson TL, Grant I. A comparison of injection and non-injection methamphetamine-using HIV positive men who have sex with men. Drug Alcohol Depend 2004;76:203-212.

14. Herdy A. Gay men gain "confidence," lose control with meth use. Denver Post March 14, 2006, p. A-1.

15. Wohl AR, Johnson DF, Lu S, et al. HIV risk behaviors among African American men in Los Angeles County who self-identify as heterosexual. J Acquir Immune Defic Syndr 2002;31:354-360.

16. Nemoto T, Operario D, Soma T. Risk behaviors of Filipino methamphetamine users in San Francisco: Implications for prevention and treatment of drug use and HIV. Public Health Rep 2002;117(Suppl 1):S30-38.

17. Diaz RM, Heckert AL, Sanchez J. Reasons for stimulant use among Latino gay men in San Francisco: A 
comparison between methamphetamine and cocaine users. J Urban Health 2005;82(1 Suppl 1):i71-78.

18. Harris NV, Thiede H, McGough JP, Gordon D. Risk factors for HIV infection among injection drug users: Results of blinded surveys in drug treatment centers, King County, Washington 1988-1991. J Acquir Immune Defic Syndr 1993;6:1275-1282.

19. Kral AH, Bluthenthal RN, Lorvick J, Gee L, Bacchetti P, Edlin BR. Sexual transmission of HIV-1 among injection drug users in San Francisco, USA: Risk-factor analysis. Lancet 2001;357:1397-1401.

20. Darke S, Cohen J, Ross J, Hando J, Hall W. Transitions between routes of administration of regular amphetamine users. Addiction 1994;89:1077-1083.

21. Scheer S, Peterson I, Page-Shafer K, et al. Sexual and drug use behavior among women who have sex with both women and men: Results of a population-based survey. Am J Public Health 2002;92:1110-1112.

22. Methamphetamine use and HIV risk behaviors among heterosexual men-Preliminary results from five northern California counties, December 2001-November 2003. MMWR Morb Mortal Wkly Rep 2006;55:273-277.

23. Page-Shafer K, Veugelers PJ, Moss AR, Strathdee S, Kaldor JM, van Griensven GJ. Sexual risk behavior and risk factors for HIV-1 seroconversion in homosexual men participating in the Tricontinental Seroconverter Study, 1982-1994. Am J Epidemiol 1997;146: 531-542.

24. Chesney MA, Barrett DC, Stall R. Histories of substance use and risk behavior: precursors to HIV seroconversion in homosexual men. Am J Public Health 1998;88:113-116.

25. Buchacz K, Patel P, Taylor M, et al. Syphilis increases HIV viral load and decreases CD4 cell counts in HIVinfected patients with new syphilis infections. Aids 2004;18:2075-2079.

26. Hirshfield S, Remien RH, Walavalkar I, Chiasson MA. Crystal methamphetamine use predicts incident STD infection among men who have sex with men recruited online: A nested case-control study. J Med Internet Res 2004;6:e41.

27. Wong W, Chaw JK, Kent CK, Klausner JD. Risk factors for early syphilis among gay and bisexual men seen in an STD clinic: San Francisco, 2002-2003. Sex Transm Dis 2005;32:458-463.

28. Nath A, Maragos WF, Avison MJ, Schmitt FA, Berger JR. Acceleration of HIV dementia with methamphetamine and cocaine. J Neurovirol 2001;7:66-71.

29. Langford D, Adame A, Grigorian A, et al. Patterns of selective neuronal damage in methamphetamine-user AIDS patients. J Acquir Immune Defic Syndr 2003;34:467-474.

30. Reback CJ, Larkins S, Shoptaw S. Methamphetamine abuse as a barrier to HIV medication adherence among gay and bisexual men. AIDS Care 2003;15:775785.

31. Ellis RJ, Childers ME, Cherner M, Lazzaretto D, Letendre S, Grant I. Increased human immunodefi- ciency virus loads in active methamphetamine users are explained by reduced effectiveness of antiretroviral therapy. J Infect Dis 2003;188:1820-1826.

32. Shaner JW, Kimmes N, Saini T, Edwards P. "Meth mouth": Rampant caries in methamphetamine abusers. AIDS Patient Care STD 2006;20:146-150.

33. Saini T, Edwards PC, Kimmes NS, Carroll LR, Shaner JW, Dowd FJ. Etiology of xerostomia and dental caries among methamphetamine abusers. Oral Health Prev Dent 2005;3:189-195.

34. Gossop M, Darke S, Griffiths P, et al. The Severity of Dependence Scale (SDS): psychometric properties of the SDS in English and Australian samples of heroin, cocaine and amphetamine users. Addiction 1995;90: 607-614.

35. Topp L, Mattick RP. Choosing a cut-off on the Severity of Dependence Scale (SDS) for amphetamine users. Addiction 1997;92:839-845.

36. Dean JA SD, Brendal KA, Arner TG, Dean AG. Epi Info (6.04d) A Database and Statistics Program for Public Health Professionals, 1994.

37. Mansergh G, Colfax GN, Marks G, Rader M, Guzman $\mathrm{R}$, Buchbinder S. The Circuit Party Men's Health Survey: findings and implications for gay and bisexual men. Am J Public Health 2001;91:953-958.

38. Shoptaw S, Reback CJ, Frosch DL, Rawson RA. Stimulant abuse treatment as HIV prevention. J Addict Dis 1998;17:19-32.

39. Harrigan PR, Hogg RS, Dong WW, et al. Predictors of HIV drug-resistance mutations in a large antiretroviral-naive cohort initiating triple antiretroviral therapy. J Infect Dis 2005;191:339-347.

40. Parienti JJ, Massari V, Descamps D, et al. Predictors of virologic failure and resistance in HIV-infected patients treated with nevirapine- or efavirenz-based antiretroviral therapy. Clin Infect Dis 2004;38:1311-1316.

41. CDC. Incorporating HIV Prevention into the Medical Care of Persons Living with HIV: Recommendations of CDC, the Health Resources and Services Administration, the National Institutes of Health, and the HIV Medicine Association of the Infectious Diseases Society of America. Atlanta, GA: MMWR 2003;52(No. RR12); 2003, 1-24.

42. Margolis AD, Wolitski RJ, Parsons JT, Gomez CA. Are healthcare providers talking to HIV-seropositive patients about safer sex? AIDS 2001;15:2335-2337.

43. Marks G, Richardson JL, Crepaz N, et al. Are HIV care providers talking with patients about safer sex and disclosure?: A multi-clinic assessment. AIDS 2002;16: 1953-1957.

44. Reback CJ, Larkins S, Shoptaw S. Changes in the meaning of sexual risk behaviors among gay and bisexual male methamphetamine abusers before and after drug treatment. AIDS Behav 2004;8:87-98.

45. Stall RD, Paul JP, Barrett DC, Crosby GM, Bein E. An outcome evaluation to measure changes in sexual risk-taking among gay men undergoing substance use disorder treatment. J Stud Alcohol 1999;60:837845 . 
46. Peck JA, Reback CJ, Yang X, Rotheram-Fuller E, Shoptaw S. Sustained reductions in drug use and depression symptoms from treatment for drug abuse in methamphetamine-dependent gay and bisexual men. J Urban Health 2005;82(1 Suppl 1):i100-108.

47. Rawson RA, Huber A, Brethen P, et al. Status of methamphetamine users 2-5 years after outpatient treatment. J Addict Dis 2002;21:107-119.

48. Campsmith ML, Nakashima AK, Jones JL. Association between crack cocaine use and high-risk sexual behaviors after HIV diagnosis. J Acquir Immune Defic Syndr 2000;25:192-198.

49. Crosby GM, Stall RD, Paul JP, Barrett DC. Substance use and HIV risk profile of gay/bisexual males who drop out of substance abuse treatment. AIDS Educ Prev 2000;12:38-48.

Address reprint requests to: Dr. Sheldon R. Morris California Department of Health Services STD Control Branch 850 Marine Bay Parkway Building $P$, 2nd Floor Richmond, CA 94804-6403

E-mail: smorris2@dhs.ca.gov 